\title{
Adult Nonmedical Prescription Drug Use: An Examination of Bond Theory
}

By: Cindy Brooks Dollar, Bradley Ray

Dollar, C. B., \& Ray, B. (2013). Adult Nonmedical Prescription Drug Use: An Examination of Bond Theory. Deviant Behavior, 34(11), 932-949. doi: 10.1080/01639625.2013.800406

This is an Accepted Manuscript of an article published by Taylor \& Francis Group in Deviant Behavior on 17 Jul 2013, available online at: http://www.tandfonline.com/10.1080/01639625.2013.800406.

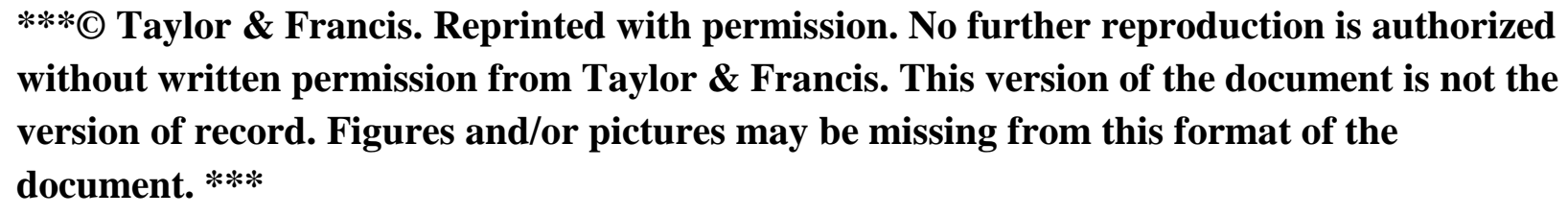
without written permission from Taylor \& Francis. This version of the document is not the version of record. Figures and/or pictures may be missing from this format of the document. $* * *$

\begin{abstract}
:
Using data from the 2010 National Survey of Drug Use and Health (NSDUH), this research examines the extent to which social bonds predict nonmedical prescription drug use among adults. Logistic regression analyses reveal that marital bonds are consistently and negatively related to various types of nonmedical drug use net other social and medical factors; however, employment bonds are only significant and negative in models predicting nonmedical pain reliever use. Analyses of interaction terms between gender and social bonds are examined but are found non-predictive. Issues concerning a lack of data availability for adult nonmedical drug use and the quality of adult bonds are discussed.
\end{abstract}

Keywords: Social Bonds | Drug Abuse | Nonmedical Prescription Drug Use

Article:

\section{INTRODUCTION}

Causes of illicit drug use have long been of interest to criminologists and sociologists. Previous research regarding illicit drug use consistently indicates that the presence of pro-social bonds deters illicit drug use (e.g., Hartwell 2003; Bahr et al. 1998; Seydlitz and Jenkins 1998; SokolKatz et al. 1997; Krohn et al. 1997; Hoffman 1995). Much of this research is guided by social control theory, which hypothesizes that when individuals lack ties to conventional social relationships and institutions, they are more likely to engage in delinquent behaviors. Previous literature on the link between social bonds and drug use, however, has largely excluded nonmedical prescription drugs in its investigations. Of the few studies that have been conducted, all of them have investigated adolescent and young adult samples including persons 25 years and younger (e.g., Ford 2008a, 2008b, 2008c, 2009; Ford and Schroeder 2009; Schroeder and 
Ford 2012). Such limited samples obstruct our knowledge about use patterns of adults, who are often the users of these drugs.

Nonmedical prescription drug use refers to the use of prescription medications, without a prescription, for the purposes of experiencing or feeling the effects of the drug. This includes taking prescription drugs other than in the manner or for the reasons prescribed, or taking a medication that was prescribed to another person (UNODC 2011). There is growing public health concern over the potential misuse of prescription drugs. The rate of nonmedical prescription drug use increased by 94\% from 1992 to 2003 (CASA 2005), and prescription drugs are now being more widely misused than any specific illicit drug, excluding marijuana (Johnston et al. 2005). Prescription drugs have replaced cocaine and heroin as the leading cause of fatal drug overdoses (Bohnert et al. 2010; Paulozzi and Xi 2008) and now account for more than half a million emergency room visits a year (DAWN 2010).

Criminologists and sociologists have only recently started to examine the causes of nonmedical prescription drug use, but have focused largely on explaining use patterns among adolescents (Ford 2008a, 2008b, 2008c, 2009; Ford and Schroeder 2009; Hall et al. 2010; Havens et al. 2011; McCabe and Teter 2007; Peralta and Steele 2010; Schroeder and Ford 2012; Seaman and Zullig 2011). While rates of nonmedical prescription drug use are higher among adolescents, recent research suggests that older adults and females are prevalent users (Compton and Volkow 2006; Han et al. 2009; McCauley et al. 2009; SAMHSA 2003; Simoni-Wastila et al. 2004).

In this research we use social control theory to examine nonmedical prescription drug use. The social control perspective assumes that all individuals are equally enticed to commit deviance but that the presence of conventional social bonds restrains these behaviors (Hirschi 1969). While the theory was originally formulated to explain juvenile delinquency, Sampson and Laub's $(1990,1993)$ seminal work on age-graded informal social control extends the bond-criminality hypothesis, arguing that social bonds remain important throughout the life-course. Thus, social control theory is ideal for examining nonmedical prescription drug use among adults and predicts that pro-social bonds during adulthood should reduce the likelihood of using these substances.

\section{LITERATURE REVIEW}

\section{Social Bonds and Drug Abuse}

Social control theories posit that the presence of conventional social bonds restrains deviant behaviors. Hirschi's (1969) formulation of social control theory has garnered a great deal of attention in the criminological literature. He hypothesized that deviance is constrained by four mutually reinforcing elements: attachment to others, commitment to and belief in conventional institutions, and involvement with conventional activities. In other words, bonds establish ties to individuals and institutions, which discourage delinquency as delinquent acts are perceived to jeopardize desired relationships or aspirations. Hirschi's original formulation of the theory focused on explaining juvenile delinquency. As such, he emphasized the importance of parent- 
child and teacher-student bonds. However, Sampson and Laub's (1993; Laub and Sampson 2003) work on age-graded informal social control has extended the bond-criminality hypothesis by arguing that social bonds remain important throughout the life-course. Positing that the benefits of social bonds accumulate over time, Sampson and Laub (1993) theorize that adult situational arrangements, such as marriage and job stability, increase an individual's resistance to delinquent behaviors. Empirical investigations of informal age-graded theory focuses nearly exclusively on predicting desistance from delinquency (Laub and Sampson 2003; Sampson and Laub 1990, 1993; Sampson et al. 2006); however, their work provides important elaborations about the importance of social bonds throughout adulthood.

Unlike many types of deviant behavior, drug use often continues through adolescence (Akers and Lee 1999). Studies investigating the relationship between adult social bonds and delinquent activity have consistently found that - like childhood bonds - adult bonds deter illicit substance use (e.g., Hoffman 1995; Yamaguchi and Kandel 1985). Duncan and colleagues (2006) found that marriage, in particular, decreases participation in binge drinking and illicit marijuana use, especially among men. However, other studies suggest that the relationship may be more complicated than previously suggested.

Research by Giordano and her colleagues indicates that the relationship between bonds and crime should emphasize the role of agency and the "cognitive transformations" that offenders undergo before they desist (e.g., Giordano et al. 2002, 2003). They argue that the bonds of marriage and employment are not simply “turning points”- as Sampson and Laub (1993) suggest - but that individuals are more or less likely to see these bonds as attractive opportunities for change and to take advantage of them. ${ }^{1}$ Focusing specifically on desistance of illicit drug use, Thompson and Petrovic (2009) investigated how the presence and quality of adult social attachments may differ among males and females. They found that being married reduced men's drug use behaviors but did not reduce women's drug use behaviors. This finding illustrates important gender differences between adult social bonds and drug use.

\section{Nonmedical Prescription Drug Use: Adult and Female User Patterns}

While use of some illicit drugs, such as cocaine, decreased throughout the early 2000s, the use of nonmedical prescription drugs substantially increased (SAMHSA 2010). ${ }^{2}$ With the exception of cannabis, prescription drugs are the most widely misused drug category (Johnston et al. 2005). In 2010, the National Survey on Drug Use and Health (NSDUH) reported that approximately 7 million people had used prescription drugs for nonmedical purposes in the past month (SAMHSA 2010). With the exception of the work done by Ford and colleagues (e.g., Ford 2009, 2008c; Ford and Arrastia 2008; Ford and Schroeder 2009; Schroeder and Ford 2012), research on nonmedical prescription drug use has been atheoretical and has focused largely on identifying demographic patterns of users. 
These descriptive studies show that in the past two decades the proportion of adolescents (ages 12-17) using prescription drugs nonmedically was higher than that of adults (ages 18 and older); however, recent trends show this gap is narrowing. In particular, the prevalence of nonmedical prescription drug use among older adults and women is increasing. ${ }^{3}$ In fact, since 2009 adolescent use has been decreasing, while the percentages of the adult populations-particularly those in their early 30s-have been increasing (SAMHSA 2010).

It is likely that the ages of nonmedical prescription drug users will continue to rise as users age through their lifecourse. Treatment Episode Data (TEDS) show that older adult users (55 years of age and older) report beginning illegal substance use prior to age 30 (Arndt et al. 2002). When looking at nonmedical prescription drugs, this pattern holds with estimates suggesting that $72 \%$ of adults initially report using nonmedical drugs prior to age 30 (Han et al. 2009). ${ }^{4}$ From 1980 to 2007, the U.S. population under 18 years fell from 28 to 25\%, while the number aged 45 to 64 increased from 20-25\% (UNODC 2011). Colliver and colleagues (2006) estimate that the number of nonmedical prescription drug users aged 50 and older is expected to double-from 911,000 to 2.7 million - by 2020 (also see Compton and Volkow 2006). Since adult nonmedical prescription drug use is expected to become a greater public health concern, it is important to gain an understanding as to what factors are associated with misuse.

Women also represent an at-risk group for nonmedical prescription drug use. In fact, among 12 17-year-olds, women exceed males in all types of nonmedical prescription drugs (i.e., pain relievers, tranquilizers, and stimulants). Unlike males, however, adult females who use nonmedical prescription drugs are rarely poly-substances users meaning that users rely solely on the misuse of prescription drugs (CASA 2005). To study this pattern, Simoni-Wastila and colleagues (2004) examined data from the 1991 National Household Survey on Drug Abuse. The authors found that women are $43 \%$ more likely to use nonmedical prescription drugs net of health status, demographics, and daily alcohol and illicit drug use. They suggest that potential risk factors for nonmedical prescription drug use are being female, unmarried, aged over 34, Caucasian, completing high school, having poor health, and drinking alcohol daily (SimoniWastila et al. 2004). Other research suggests that women's use of nonmedical drugs might be the result of an increased likelihood to suffer from post-traumatic stress as the result of past trauma (McCauley et al. 2009) or because women are more likely to have been prescribed drugs with the potential of abuse, such as painkillers and minor tranquilizers (Hohmann 1989; SimoniWastila 1998).

Despite the prevalence of nonmedical use among adults, criminological research has focused exclusively on adolescent use (e.g., Ford 2008a, 2008b, 2008c, 2009; Ford and Schroeder 2009; Hall et al. 2010; Schroeder and Ford 2012). To date, no studies have used criminological theory to examine nonmedical prescription drug use among adults. Given the increasing use patterns and the demographics of users, further investigation of prescription drug misuse is warranted. Using data collected from the 2010 National Survey on Drug Use and Health (NSDUH), the present article investigates how adult social bonds predict nonmedical prescription drug use. 
Moreover, because research indicates that social bonds may operate differently for males and females (Thompson and Petrovic 2009), the present analysis examines whether the relationship between adult social bonds and non-prescribed prescription drug use is contingent on gender.

\section{METHOD AND DATA}

\section{Sample}

The analysis uses data from the 2010 NSDUH. NSDUH provides the most comprehensive data regarding prevalence and correlates of drug use as well as demographic information including respondents' age, gender, race, ethnicity, health status, marital status, and job status.

Respondents are asked about lifetime use, annual use, and monthly use of marijuana, cocaine, crack, hallucinogens, heroin, inhalants, alcohol, tobacco, and nonmedical use of prescription drugs, including pain relievers, tranquilizers, stimulants, and sedatives.

Using a multistage stratified probability sample for all 50 states and the District of Columbia, NSDUH collects information from non-institutionalized civilian members of U.S. households, who are aged 12 and older. Since the present analysis is interested in investigating the nonmedical use of prescription drugs among adults, we select only those respondents who report being 18 years and older $(n=38,067) .{ }^{5}$ It is important to note that NSDUH is designed to collect drug use data from an approximately equal number of persons in two distinct adult groups: young adults (defined as ages 18 to 25) and other adults (defined as 26 years and older). In an effort to gather information across a variety of age ranges, the sampling allocation process targets four adult age-group strata: 18 to 25 years of age, 26 to 34 years of age, 35 to 49 years of age, and 50 years and older. NSDUH conducts sample weighting at the person and household level. Each weight component accounts for an adjustment for non-response and an adjustment for sampling coverage. Thus, although age-group strata are sampled at different rates with young adults being oversampled, NSDUH's sampling strategies are designed to produce a sample that is generalizable to the noninstitutionalized U.S. population. (For a full description of NSDUH's sampling and selection procedures, see the 2010 NSDUH Data Collection Final Report and 2010 NSDUH Public Use File Codebook.)

\section{Measures}

\section{Nonmedical Drug Use}

We use nonmedical prescription drug use in the past year as our dependent variable. NSDUH defines nonmedical prescription drug use as taking a prescription drug that was not prescribed or taking the drug only for the experience or feeling it caused. The prescription drug types contained in this analysis include pain relievers (OxyContin, Darvocet, Percocet, Vicodin, codeine, Dilaudid, Methadone, morphine, Stadol), tranquilizers (Klonopin, Xanax, Valium, Flexeril, Soma), stimulants (methamphetamine, amphetamine, Dexedrine, Ritalin, Adderall), and sedatives (Ambien, Restoril, Halcion). ${ }^{6}$ After defining nonmedical prescription drug use, the 
respondent was asked a series of questions about their nonmedical use of various prescription drugs. Probes designed to identify nonmedical use of any prescription drug were also included in order to identify respondents who took prescription drugs nonmedically even if there were unsure of the particular brand, type or classification of drug.

Because we are interested in prevalence, rather than frequency, of use, we assessed dichotomous measures of past-year nonmedical prescription drug use ( 0 = no use; 1 = reported use). Below, we report our analyses of total or overall nonmedical prescription drug use within the past year; however, relying only on total use patterns may mask variation across drug types. Blazer and $\mathrm{Wu}$ (2009) concluded that opiates were most likely to be used nonmedically by older adults, followed by tranquilizers, stimulants, and sedatives. To account for potential variations across drug type and reveal any substantively important differences among the drug categories, we examine and report use patterns separately for each drug classification type (i.e., pain reliever, tranquilizer, stimulant, and sedative).

\section{Adult Social Bonds}

The dataset contains information on two types of relevant adult social bonds: marital and employment bonds. Prior research has recognized marriage as an important determinant of adult drug use (Duncan et al. 2006; Yamaguchi and Kandel 1985; West1982; Osborn and West 1979). Although there is some indication that marital satisfaction and parental status may be important determinants of drug use (Haynie et al. 2005; Lui and Kaplan 2001; Daly 1994; Sampson and Laub 1993; Yamaguchi and Kandel1985), the present data do not contain this information. The present analysis measures marital status dichotomously ( 1 = currently married, 0 = not currently married). Respondents who report not being currently married, include those who reported being widowed, separated, divorced, and never married.

Employment status (Sampson and Laub 1993) and the number of hours worked per week (Thompson and Petrovic 2009) are commonly used as indicators of adult work bonds. These measurements serve as an appropriate assessment of two social bond components: the level of attachment an individual has to her or his employment and the time committed to conventional activities. We examined two measures of employment status. One measure asks respondents to report employment status by indicating whether they were employed full-time, part-time, or unemployed during the past year. From this item, we also computed a dichotomous employed/unemployed item. Our analysis revealed no significant differences between the models; therefore, we report the findings for the dichotomous employed (1) and unemployed (0) respondents below.

\section{Controls}

Additional variables, including respondents' gender, race, age, other drug use, mental health status, and overall health status, are included as controls in the present analysis. With the exception of age, which is measured categorically, each control variable is measured 
dichotomously. Demographic variables are included based on prior empirical research. The present analysis examines the main and interaction effects of the respondent's sex and direct effects of age, race, and ethnicity.

Prior research indicates differences in male and female drug use patterns as well as a gendered effect of social bonds that finds males and females' bonds may differentially influence delinquent outcomes, including illicit substance use (Duncan et al. 2006; Simoni-Wastila et al. 2004; Thompson and Petrovic 2009). To examine these direct and interaction effects, we create a dummy-scored measure of the respondent's sex $(1=$ Female). Although social control theory does not directly hypothesize a race or ethnicity effect on delinquency, recent research has suggested that race-ethnicity and social bonds may be related (Ellickson et al.1999;

Wallace 1998). Further, Harrell and Broman (2009) found that the correlates of prescription drug misuse differed among whites, blacks, and Hispanics. We operationalize race and ethnicity using a series of dummy variables, including non-Hispanic whites, non-Hispanic blacks, non-Hispanic other race, and Hispanic. The category of "non-Hispanic other race” includes non-Hispanic Native Americans, Alaskan Natives, Native Hawaiians, other Pacific Islanders, Asians, and biracial respondents. Whites are included as the reference category.

Research on drug desistance indicates that age is an important factor in determining drug use patterns (Laub and Sampson 2003; Sampson and Laub 1990, 1993; Sampson et al. 2006). The NSDUH's dataset does not include information about the respondents' actual age or date of birth. Rather, they provide several edited age variables, which categorize respondent's age in as few as 2 and up to 17 categories. To remain consistent with the age-group strata used in the sampling allocation process, we measure age using a series of dummy variables for the following age categories: 18-25 years, 26-34 years, 35-49 years, and 50 years of age or older. Given our interest in adult prescription drug misuse and the previous research on nonmedical drug use of persons 25 years and younger (e.g., Ford 2009; Ford and Schroeder 2009), we use the 18-25 age group as the reference category.

Prior research indicates that other types of substance use, mental health status, and overall health status may be related to current non-prescribed prescription drug use (e.g., Drake et al. 1998, 2007; Herman-Stahl et al. 2007; Iguchi et al. 1993; McCabe et al. 2006; Simoni-Wastila et al. 2004). Thus, we control for these factors. We computed a dichotomous measure of other illicit substances by combining the respondents' reported use of cocaine, heroin, hallucinogens, and inhalants within the past year. Consistent with prior research (Thompson and Petrovic 2009; Maume et al. 2005), we excluded marijuana use; however, supplemental analyses revealed that including marijuana use in the index did not significantly change the substantive findings. Further, since research had previously demonstrated that overuse of alcohol may be related to nonmedical drug use (Simoni-Wastila et al. 2004), we created an alternative index of other illicit substances that included heavy alcohol consumption defined as drinking five or more drinks at a single sitting or within a couple of hours in the past 30 days. Again, analyses revealed that including this indicator in the index did not significantly change the substantive findings. 
We examined mental health in two ways. Our first measure of mental health status was informed by two survey response items. Respondents reported whether they had received (1) in-patient or (2) out-patient mental health treatment in the last 12 months that was unrelated to alcohol or drug use. Using these two items, we calculated a dummy variable that was coded 1 if a respondent reported receiving in- or out-patient mental health treatment in the past year, and 0 if the respondent reported no such treatment. Our second measure of mental health status included three items wherein respondents were asked whether or not they had experienced depression, counseling, and/or mental health treatment in the past year. Factor analysis revealed that these three items formed a single factor (eigenvalue 1.5). Our analysis reveals no significant differences between these measures; therefore, we report results using the dummy-coded measure below.

Finally, we compute a dichotomous measure of overall health status using a single response item. Respondents report their overall health status using a five-category response. We combined the first three response options (excellent, very good, and good) into a single "good" response, and the last two original responses (fair and poor) into a "fair/poor" response. Overall health was dummy-scored 1 if the respondent reported good health.

\section{ANALYTIC STRATEGY}

We use logistic regression to model past-year nonmedical prescription drug use. In order to separately assess the direct effect of the control variables, direct effects of each social bond measure and the interaction effects of gendered bonds on nonmedical drug use, we conduct a series of stepwise regression analysis. Below, we report our findings for total nonmedical use as well as nonmedical pain reliever, tranquilizer, stimulant and sedative use. We present our results by first discussing the effects of our control variables on nonmedical drug use. We then review the direct effects of marital and employment bonds on each form of nonmedical drug use before turning our attention to the analysis of gendered bonds (interaction models).

\section{RESULTS}

Table 1 presents descriptive statistics of our total adult sample $(N=38,067)$. The percentage of males and females is nearly equal with females comprising 53\% of the sample. Approximately $63 \%$ of the respondents are non-Hispanic whites. Because NSDUH's dataset does not include the respondent's actual age in years, we are unable to calculate a true mean of respondent's age; however, the available data suggest that the midpoint age is approximately 25 years. Thirty-five percent of the adult respondents report being currently married $(n=13,512)$, and nearly $67 \%$ are employed at least part time $(n=25,389)$.

Table 1 Descriptive Statistics for all Variables $(\mathrm{N}=38,067)$

\begin{tabular}{|l|l|l|l|}
\hline Variable & Mean & SD & Range \\
\hline
\end{tabular}




\begin{tabular}{|l|l|l|l|}
\hline Female & .53 & .49 & $0-1$ \\
\hline White & .63 & .48 & $0-1$ \\
\hline Black & .12 & .32 & $0-1$ \\
\hline Hispanic & .16 & .36 & $0-1$ \\
\hline Other Race & .09 & .28 & $0-1$ \\
\hline Age & $25^{ \pm}$ & 2.94 & $18-65$ \\
\hline Other Drug Use (Yes) & .07 & .24 & $0-1$ \\
\hline Treated for Mental Health (Yes) & .08 & .29 & $0-1$ \\
\hline Overall Health (Good) & .90 & .29 & $0-1$ \\
\hline Marital Bond (Married) & .35 & .47 & $0-1$ \\
\hline Work Bond (Employed) & .67 & .47 & $0-1$ \\
\hline General Nonmedical Use & .102 & .30 & $0-1$ \\
\hline Pain Reliever Use & .082 & .27 & $0-1$ \\
\hline Tranquilizer Use & .038 & .18 & $0-1$ \\
\hline Stimulant Use & .023 & .14 & $0-1$ \\
\hline Sedative Use & .004 & .06 & $0-1$ \\
\hline
\end{tabular}

The mean for dichotomous measures can be interpreted as a percentage. \pm NSDUH does not include the respondent's actual age in years, so we are unable to calculate a mean of respondent's age. The available data suggest that this is the approximate median of age.

Over $10 \%$ of respondents report using prescription drugs nonmedically in the past year $(n=3,898)$. In examining use distribution by drug type, we find that over $8 \%$ of respondents report using pain relievers $(n=3,103)$, about $4 \%$ reported using tranquilizers $(n=1,402), 2 \%$ reporting using stimulants $(n=812)$, and only $0.4 \%$ of respondents reporting using sedatives nonmedically $(n=151)$.

Additionally, consistent with prior studies (Simoni-Wastila et al. 2004), our data indicate that males who report nonmedical prescription drug use are nearly twice as likely to be polydrug users. Our data indicate that approximately $60 \%$ of males who use prescription drugs 
nonmedically report using other illicit drugs as well, whereas only $41 \%$ of females report such polydrug use. This nearly $20 \%$ percentage point difference is statistically significant $\left(\chi^{2}=50.94, p>.05\right.$, results not shown).

\section{Regressions}

Table 2 illustrates the results of our logistic regression analysis. Below we report the results for each model, which examine patterns of total nonmedical use and nonmedical pain reliever, tranquilizer, stimulant, and sedative use. The models indicate that several variables are statistically significant predictors of non-prescribed prescription drug use; however, predictors vary slightly by drug type.

Table 2 Nonmedical Prescription Drug Use Regressed on Control Variables and Social Bonds

\begin{tabular}{|c|c|c|c|c|c|}
\hline Variables & Total Use & $\begin{array}{l}\text { Pain } \\
\text { Relievers }\end{array}$ & Tranquilizers & Stimulant & Sedative \\
\hline \multicolumn{6}{|l|}{ Controls } \\
\hline Female & $\begin{array}{l}-0.26 \\
{[.96]}\end{array}$ & $-.13 *[.87]$ & $.19 *[1.21]$ & $.26 *[1.33]$ & $-.35[.71]$ \\
\hline Black & $\begin{array}{l}-.67^{*} \\
{[.50]}\end{array}$ & $-.54 *[.59]$ & $-.99 *[.37]$ & $\begin{array}{l}-1.19 * \\
{[.38]}\end{array}$ & $\begin{array}{l}-.58 * * \\
{[.56]}\end{array}$ \\
\hline Hispanic & $\begin{array}{l}-.58^{*} \\
{[.56]}\end{array}$ & $-.56 *[.57]$ & $-.83 *[.43]$ & $-.67 *[.51]$ & $.00[1.00]$ \\
\hline Other Race-Ethnicity & $\begin{array}{l}-.35^{*} \\
{[.70]}\end{array}$ & $-.31 *[.73]$ & $-.54 *[.58]$ & $-.28 *[.76]$ & $-.43[.65]$ \\
\hline Age 26-34 & $\begin{array}{l}-.23^{*} \\
{[.79]}\end{array}$ & $-.25 *[.78]$ & $-.14[.87]$ & $-.24 *[.78]$ & $.15[1.16]$ \\
\hline Age 35-49 & $\begin{array}{l}-.58^{*} \\
{[.56]}\end{array}$ & $-.66 *[.52]$ & $-.29 *[.75]$ & $-.47 *[.63]$ & $.25[1.28]$ \\
\hline Age 50 and Older & $\begin{array}{l}-1.51 * \\
{[.22]}\end{array}$ & $-1.65 *[.19]$ & $-1.24 *[.29]$ & $\begin{array}{l}-2.27^{*} \\
{[.10]}\end{array}$ & $-.15[.86]$ \\
\hline Other Drug Use (Yes) & $\begin{array}{l}2.36^{*} \\
{[10.60]}\end{array}$ & $2.28 *[9.72]$ & $2.54 *[12.65]$ & $\begin{array}{l}2.45^{*} \\
{[11.55]}\end{array}$ & $\begin{array}{l}2.18^{*} \\
{[8.83]}\end{array}$ \\
\hline $\begin{array}{l}\text { Treated for Mental } \\
\text { Health (Yes) }\end{array}$ & $\begin{array}{l}61^{*} \\
{[1.84]}\end{array}$ & $.50 *[1.65]$ & $.66 *[1.96]$ & $.69 *[1.99]$ & $\begin{array}{l}1.00^{*} \\
{[2.73]}\end{array}$ \\
\hline
\end{tabular}




\begin{tabular}{|l|l|l|l|l|l|}
\hline Health (Good) & $\begin{array}{l}-.30^{*} \\
{[.74]}\end{array}$ & $-.39^{*}[.68]$ & $-.10[.90]$ & $-.17[.84]$ & $-.36[.70]$ \\
\hline Social Bonds & \multicolumn{5}{|l|}{} \\
\hline Married & $\begin{array}{l}-.44^{*} \\
{[.64]}\end{array}$ & $-.37^{*}[.69]$ & $-.22^{*}[.80]$ & $-.79^{*}[.45]$ & $-.59[.55]$ \\
\hline Employed & $-.06[.94]$ & $-.12^{*}[.89]$ & $.00[.1 .00]$ & $-.09[.92]$ & $-.29[.75]$ \\
\hline Gendered Social Bonds (Interaction Models) & \multicolumn{1}{l|}{} \\
\hline Female*Married & $.01[1.01]$ & $-.03[.96]$ & $-.15[.85]$ & $-.03[.97]$ & $.51[1.66]$ \\
\hline Female*Employ & $-.02[.97]$ & $.02[1.02]$ & $-.00[.99]$ & $-.26[.81]$ & $.62[1.86]$ \\
\hline
\end{tabular}

Table entries are unstandardized (metric) regression coefficients (odds ratio in brackets). $* \mathrm{p} \leq .05 ; * * \mathrm{p} \leq .10$.

Models predicting overall or total nonmedical drug use $(n=3,886)$ indicate that race, ethnicity, age, other drug use, mental health status and overall health status are all significant predictors. Specifically, racial-ethnic minorities $(\mathrm{OR}=0.50,0.56,0.70)$ and older respondents (odds ratio $[\mathrm{OR}]=0.79,0.56,0.22$ ) are less likely to report nonmedical prescription drug use than whites and younger (18-25 years of age) respondents. In addition, persons who use other drugs are substantially more likely to misuse prescription drugs. In fact, other drug use is the strongest predictor of non-prescribed drug use. Respondents who report using other drugs are about 11 times more likely to report misusing prescription drugs $(\mathrm{OR}=10.60)$. Finally, respondents receiving mental health treatment in the past year are nearly twice as likely to report nonmedical prescription drug use as respondents not receiving such care $(\mathrm{OR}=1.84)$, and those reporting good health are less likely to use prescription drugs nonmedically ( $\mathrm{OR}=0.74)$.

Pain relievers are the most common drug misused in the population from which the data are drawn. In fact, of those persons reportedly using prescription drugs nonmedically in the past year, about $8 \%(n=3,103)$ report using pain relievers. Models predicting pain relievers are similar to the general nonmedical use prediction model; however, the data suggest that when examining this specific drug type, females are significantly less likely to report nonmedical pain reliever use as compared to males. In fact, females are about $13 \%$ less likely than males to report using pain relievers nonmedically $(\mathrm{OR}=0.87)$.

The present data reveal that of those persons reportedly using prescription drugs nonmedically in the past year, $36 \%$ of respondents have misused tranquilizers and just over $21 \%$ have misused stimulants ( $n=1,402$ and 812 , respectively). Findings related to nonmedical tranquilizer and stimulant use are largely consistent with those of pain relievers. The data reveal that persons of a minority race and ethnicity are less likely to misuse these drugs as compared to whites. 
Additionally, persons who have received mental health treatment and used other drugs illicitly continue to be more likely to misuse tranquilizers and stimulants than those who have not received such treatment or misused other drugs (see Column 3 and 4, Table 2). Also, in regards to stimulant misuse, all older age groups are less likely to report such use as compared with persons who are 18-25-year-olds. We do identify two notable differences, however, between these models and the pain reliever model. First, the data suggest that nonmedical tranquilizer use among 18-25- and 26-34-year-olds is not significantly different although all other age groups are less likely to report tranquilizer misuse than those who are 18-25 years old (OR $=0.75$, 0.29). Second, while gender continues to be a significant predictor of nonmedical tranquilizer and stimulant models, the effect of gender changes directions. That is, females are more likely than males to report nonmedical use of tranquilizers and stimulants $(\mathrm{OR}=1.21,1.33$, respectively). We address the shifting association of gender in our discussion.

Survey results indicate that less than $1 \%$ of persons reporting nonmedical use of prescription drugs use sedatives $(n=151)$. In the models predicting nonmedical sedative use only mental health treatment and other drug use are significant and positive ( $\mathrm{OR}=8.83,2.73$, respectively). The largely null results may be due to the rarity of reported use.

With the exception of sedatives, which is heavily skewed toward nonuse, all of the models find that marital status is a statistically significant predictor of non-prescribed prescription drug use in the theoretically predicted direction (Total use $\mathrm{OR}=0.64$; Pain $\mathrm{OR}=0.69$, Tranquilizer $\mathrm{OR}=0.80$, Stimulant $\mathrm{OR}=0.45$ ). However, employment bonds are only related to nonmedical prescription drug use in the pain reliever model. The data indicates that persons who are employed are about $12 \%$ less likely to report nonmedical use of pain relievers than unemployed persons $(\mathrm{OR}=0.89)$.

In addition to the main effect of social bonds on prescription drug misuse, we assessed the potential for gendered social bond effects on nonmedical drug use. Prior research predicting desistance of other types of illicit drug use has indicated that marital and employment bonds vary in their effect by gender (e.g., Thompson and Petrovic 2009). As stated above, the present data also indicate significant main gender effects although the direction of the effect varies by drug type. To examine conditional effects of gender, we computed a production term to measure the interaction between gender and marital status and gender and employment status. The results of our examination are presented at the bottom of Table 2. The data reveal that neither the interaction of gender and marital status nor the interaction of gender and employment status predicts nonmedical prescription drug use, net of other factors in the model.

\section{DISCUSSION}

Prescription drug misuse is becoming increasingly prevalent. The present analysis contributes to research of nonmedical prescription drug use and extends the literature on social bonds and drug use. Even though previous research has indicated that various ties to conventional social bonds 
deter illicit drug use, including adolescent nonmedical prescription drug use, our findings indicate some variation in the effect of adult social bonds on prescription drug misuse.

In support of age-graded informal social control, adult marital bonds-operationalized using a single marital status item-is a significant predictor of nonmedical drug use across all types of drugs except sedatives, net of other factors. We argue that the lack of results in the sedative models is likely due to the low numbers of users reporting such use, which makes it difficult for the model to predict patterns. The present analysis indicates that employment bonds are a weaker and less consistent predictor of nonmedical prescription drug use than marital bonds. This finding also implies that the presence of social bonds alone may be an insufficient explanation of nonmedical drug use. Theoretical elaborations of control theory argue that the content or quality of the relationship is often a better predictor of delinquency than the mere presence of the marital relationship. For example, in their analysis of criminal desistance Giordano and colleagues (2003) found that marital and intimate partner attachment did not predict likelihood of criminal desistence. They concluded that the null relationship may be due to the nature of the marriage, which includes whether one's marital partner participates in deviance.

Additionally, Sampson and Laub $(1990,1993)$ argue that strong or quality bonds developed at any time in the life course can encourage the development of social capital (Coleman 1990), which can alter routine activities of individuals (Laub and Sampson 2003). Empirical research supports the supposition. Research indicates that marital satisfaction, job stability, and having high educational aspirations deter deviant outcomes (Sampson and Laub 1990; Laub et al. 1998; Laub and Sampson 2003), and interviews with persistent offenders revealed that obtaining a “good” job could minimize or terminate criminal careers as thieves (Shover 1996). The data available for the present analysis limit our ability to examine more nuanced measures of employment bonds; thus, the inconsistent effect of employment status on nonmedical drug use may be due to our rudimentary employment bond measure.

The present analysis indicates a strong association between mental health and nonmedical prescription drug. This finding is consistent with much of the current research, which suggests that co-occurring mental health and substance abuse problems are the norm rather than the exception (Drake et al. 2007). Approximately half those with severe mental disorder are affected by substance abuse and half of all drug abusers have a least one serious mental illness (Drake et al. 1998). Of all persons diagnosed with some type of mental illness, about one-third abuse drugs or alcohol.

We find that the main effect of gender differs across the models. In models predicting overall nonmedical prescription drug use, gender is not significantly related to use; however, in models predicting pain reliever, tranquilizer, and stimulant use, gender is significant. Moreover, the data indicate that even though gender is consistently significant, it is not predictive in the same direction across drug categories. Specifically, controlling for various medical, demographic, and social variables, females are significantly less likely to report pain reliever use, but they 
are more likely to report tranquilizer and stimulant use. This finding was unexpected, but highlights that relying on models of total or overall prescription drug misuse may mask variations between drug types.

Explaining the directional change of gender across types of nonmedical prescription drug use will require further investigation, but we speculate that this pattern could emerge for a few reasons. First, some studies have found gender differences in the types of drugs prescribed, with women being more likely to be prescribed pain relievers (opiates) than men (Kelly et al. 2008; Simoni-Wastila et al. 2004), which may suggest that women are less likely to misuse pain relievers because they are more likely to receive drugs legitimately through a physician's prescription. However, a study by Jamison and colleagues (2010) found no significant gender differences in the extent of opiate misuse but did find differences in the reasons for misuse by men and women. Specifically, the authors established that males who misuse opiates were significantly more likely than females to report having peers who abuse alcohol and drugs (Jamison et al. 2010). Their results suggest that pain reliever misuse may be associated with delinquent peer networking. Scholars have previously noted the importance of peer networks in predicting delinquency (e.g., Warr 1993, 2002). Our findings, then, could be revealing a link between misuse of prescription drugs and particular social ties to others. Unfortunately, our data do not contain measures of adult peer delinquency, so we are unable to explore this relationship in the present analysis.

In addition, it is possible that difference in misuse of pain relievers as compared to tranquilizer and stimulant is related to hegemonic masculine ideals (Connell 2005). When taken legitimately, these drugs assist in resolving different medical issues. Pain relievers provide relief from pain and discomfort associated with various bodily injuries, tranquilizers are taken to resolve issues of anxiety and tension, and stimulants increase concentration and alertness and decrease appetite. Scholars have previously noted that men sometimes injure their body in demonstrations of masculinity (e.g., Messner 1992). Moreover, evidence suggests that men are less likely to seek medical treatment (Green and Pope 1999). It is possible then that men may be more likely to use pain relievers than other drugs nonmedically as a way to self-medicate issues of pain.

Even when men seek medical treatment, they often indicate feelings of uneasiness about how treatment conflicts with displays of masculinity (e.g., Brenton and Elliott 2013; Courtenay 2000; Noone and Stephens 2008). Thus, it is also plausible that men are more likely than women to use pain relievers not because they are self-medicating but because they see the misuse of pain relievers as more socially acceptable than misuse of tranquilizers and stimulants. Again, the reason for [legitimate] drug use is an important consideration. Men may regard the misuse of pain relievers as being more gender appropriate (West and Zimmerman 1987), in that such use is construed as a way to function despite a physical injury. Nonmedical use of tranquilizers and stimulants, however, may be perceived as indicating a deficiency in masculinity because the drugs are understood as resolving issues of anxiety, cognitive distraction and body weightissues that are often feminized. The present data do not include measures that allow us to 
examine how perceptions of masculinity and femininity may influence drug using behavior; however, our data revealed that men were significantly more likely than women to participate in polydrug use-a risky behavior consistent with masculine expression. Future research should empirically examine links between why people choose to misuse specific drugs to further explicate reasons for gender differences among nonmedical use across drug types.

Previous research has suggested the existence of gendered social bond effects in some types of drug use. The present research, however, does not find such an effect. One reason for this divergence may be due to the unique form of deviant drug use we examine. Although prevalent, nonmedical drug use is still rarely investigated in the deviance and sociological literature. Research has not established that gender contingent social bonds effects exist across all forms of deviance, and to our knowledge, the present study is the first to examine factors predicting adult nonmedical prescription drug use, including potential interaction effects of gender and social bonds. Moreover, the data used in the present analysis reflect current trends of drug use, whereas extant research suggesting gendered social bond effects on drug use have relied on older data that may not accurately reflect current lived experiences in relation to gender. For example, Thompson and Petrovic (2009) concluded a gendered bond effect on drug desistence using data collected in the 1970s and 1980s. The present analysis uses data from 2010, and the lack of a significant interaction may be the result of changes in the value of marital and employment bonds. In short, males and females may be more likely to converge in their understanding of the social meaning of these conventional bonds, which would mitigate any moderating effect of gender. Still, given our lack of knowledge on the topic, the gendered effects of social bonds on drug use patterns should continue to be investigated before a clear argument can be made about the presence (or lack thereof) of gendered social bond effects.

Despite the insight gained in the present analysis, there are some limitations of this study. First, defining non-prescribed drug use is difficult. The definition used by NSDUH includes any ingestion of prescription drugs that is not prescribed by a physician. It is likely, though, that some individuals use prescription drugs outside of a physician's order for legitimate medical reasons. Although these situations do involve illicit drug use, it is plausible that the cause of that particular type of use is fundamentally different than illicit drug use for recreational reasons (i.e., for the purpose of intoxication). Without being able to distinguish between nonprescribed medical and recreational use, more meaningful conclusions about the cause of nonmedical prescription drug users is concealed.

Second, NSDUH does not triangulate data on drug use; therefore, the data in the present analysis rely only on self-reported drug use. Although extant research on drug use patterns also relies largely on self-reported research, it is always a concern that self-reports may yield unreliable or invalid data. Moreover, it could be argued that persons who report attachments to conventional social bonds may be more reluctant to report drug misuse than persons who report no such attachments. 
Third, the present analysis involves a cross-sectional analysis of data. ${ }^{7}$ Although some scholars argue that cross-sectional research designs are adequate to establish the causes of delinquency (e.g., Gottfredson and Hirschi 1987), other scholars have argued that longitudinal analysis is needed to establish clear temporal ordering (Agnew 1985; Farrington et al. 1986; Wiatrowski, Griswold, and Roberts 1981). We recognize concerns in establishing cause when using data from one time point. To this end, the present analysis may not be able to fully verify the influences among the variables examined; however, we argue that this research is an important first step in investigating a prominent, yet understudied, form of deviance.

Finally, because of the data limitations, the present study employs crude measurements of social bonds. As discussed previously, prior theoretical and empirical research indicates that the presence of social bonds may be a less important predictor of deviance than relationship quality; therefore, information regarding marital and employment satisfaction and stability as well as data on the presence and quality of other types of social bonds, including non-marital romantic, peer, community, and religious attachments would provide more comprehensive measures of social control. Obtaining information about how various forms of social bonds may influence prescription drug misuse is a necessary part of explaining patterns of nonmedical prescription drug use. For instance, extant research suggests that cohabitation has some deterrent effect on adult illicit drug use even though the effect is often weaker and less consistent when compared to marriage (e.g., Bachman et al. 1997, 2002; Duncan et al. 2006). Because of a lack of data in NSDUH, we are unable to compare the effects of marriage and cohabitation on nonmedical prescription drug use. However, given the prevalence of such misuse among adults (SAMHSA 2010) and the increasing trend of cohabitation (Kreider 2010; Smock 2000), this is an important consideration for future research. In fact, such analysis could help clarify the mechanisms by which particular social bonds may discourage unlawful drug use and other forms of risky behavior.

Nonmedical use of prescription drugs is the second leading form of illicit drug use in the United States, and such misuse has been cited as a growing public health concern (Compton and Volkow 2006). Our research contributes to the growing literature on nonmedical prescription drug use by focusing attention on adult users. Given the dearth of data on adults who use prescription drugs nonmedically, studying the causal mechanisms of nonmedical prescription drug use is difficult. However, the present analysis identifies some factors related to adult prescription drug misuse and demonstrates that use patterns differ by drug type. Although NSDUH includes the most comprehensive and representative data currently available on adult prescription drug misuse, more comprehensive and theoretically driven measures, including factors related to various demographic and social factors, are needed in order to gain better understanding about the causes and increasing prevalence of nonmedical prescription drug use.

\section{Notes}


${ }^{1}$ Laub and Sampson (2003) have included notions of agency in their most recent theoretical forumulation.

${ }^{2}$ Regular or past month non-prescribed use of psychotherapeutics has remained relatively stable since 2002, but the number of new users has increased substantially (SAMHSA 2010).

${ }^{3}$ Patients, young persons, and health professionals have also been highlighted as high risk for nonmedical prescription drug use (UNODC 2011).

${ }^{4}$ Like younger adults, older adults who use nonmedical prescription drugs tend to be polysubstance users (CASA 2005).

${ }^{5}$ The authors ran a complete supplemental analysis on respondents who reported being 21 years of age or older. The results were not significantly different than those results including respondents 18 years and older. Since most prior analysis focuses on adolescents who are 17 and younger, we report the analysis of all adults aged 18 years and older.

${ }^{6}$ The drugs reported here are examples but do not include an exhaustive list of the drugs inquired about in the NSDUH.

The mean for dichotomous measures can be interpreted as a percentage.

${ }^{ \pm}$NSDUH does not include the respondent's actual age in years, so we are unable to calculate a mean of respondent's age. The available data suggest that this is the approximate median of age.

Table entries are unstandardized (metric) regression coefficients (odds ratio in brackets).

${ }^{*} p \leq .05 ; * * p \leq .10$.

${ }^{7}$ Although NSDUH is an ongoing study, it is not a panel longitudinal design.

\section{REFERENCES}

1. Agnew , Robert 1985 . "Social Control Theory and Delinquency: A Longitudinal Test.” Criminology $23: 47-61$.

2. Akers , Ronand L. and Gang Lee . 1999 . "Age, Social Learning, and Social Bonding in Adolescent Substance Use.” Deviant Behavior 20 : 1 - 25 .

3. Arndt , Stephan , Carolyn L. Turvey , and Michael Flaum . 2002 . "Older Offenders, Substance Abuse, and Treatment.”American Journal of Geriatric Psychiatry 10 : 733 - 739 .

4. Bachman , Jerald G, Patrick M. O'Malley, John E. Schulenberg, Lloyd D. Johnston , Alison L. Bryant, and Alicia C. Merline .2002 . The Decline of Substance Use in Young Adulthood: Changes in Social Activities, Roles, and Beliefs . Mahwah, NJ : Lawrence Erlbaum Associates . 
5. Bachman , Jerald G. , Katherine N. Wadsworth, Patrick M. O'Malley, Lloyd D. Johnston, and John E. Schulenberg. 1997.Smoking, Drinking, and Drug Use in Young Adulthood . Mahwah, NJ : Lawrence Erlbaum Associates.

6. Bahr , Stephan J. , Suzanne L. Maughan , Anastasios C. Marcos , and Bingdao Li . 1998 . "Family, Religiosity, and the Risk of Adolescent Drug Use." Journal of Marriage and Family 60 : $979-992$.

7. Blazer , Dan G. and Li-Tzy Wu . 2009 . "Nonprescription Use of Pain Relievers by MiddleAged and Elderly Community-Living Adults: National Survey on Drug Use and Health.” Journal of the American Geriatrics Society 57 : 1252 - 1257.

8. Bohnert , Army S. B. , Sylwia Fudalej , and Mark A. Ilgen . 2010 . "Increasing Poisoning Mortality Rates in the United States, 1999-2006.” Public Health Reports 125 : 542 - 547.

9. Brenton , Joslyn and Sinikka Elliott . 2013 . "Undoing Gender?: The Case of Complementary and Alternative Medicine.”Sociology of Health and Illness 36 ( 3 ): 1 - 17 . ISSN 0141-9889. doi: 10.1111/1467-9566.12043

10. CASA . 2005 . Under the Counter: The Diversion and Abuse of Controlled Prescription Drugs in the U.S. The National Center on Addiction and Substance Abuse at Columbia University, New York.

11. Coleman , James. 1990 . Foundations of Social Theory . Cambridge , MA : Harvard University Press .

12. Colliver , James D. , Wilson M. Compton , Joseph C. Gfroerer , and Timothy Condon . 2006 . "Projecting Drug Use among Aging Baby Boomers in 2020." Annals of Epidemiology 16 : $257-265$.

13. Compton , Wilson M. and Nora D. Volkow . 2006 . "Major Increases in Opioid Analgesic Abuse in the United States: Concerns and Strategies.” Drug and Alcohol Dependence 81 : 103 107.

14. Connell , R. W. 2005 . Masculinities, 2nd edition . Berkeley : University of California Press .

15. Courtenay , Will H. 2000 . "Engendering Health: A Social Constructionist Examination of Men's Health Beliefs and Behaviors.”Psychology of Men and Masculinity 1 ( 1 ): 4-15 .

16. Daly, Kathleen. 1994 . Gender, Crime, and Punishment . New Haven, CT : Yale University Press .

17. DAWN . 2010 . Trends in Emergency Department Visits Involving Nonmedical Use of Narcotic Pain Relievers . Drug Abuse Warning Network, Rockville, MD . 
18. Drake, Robert E. , Kim T. Mueser, and Mary F. Brunette . 2007 . "Management of Persons with Co-Occuring Severe Mental Illness and Substance Use Disorder: Program Implications.” World Psychiatry 6 : 131 - 136 .

19. Drake , Robert E. , Carolyn Mercer-McFadden , Kim T. Mueser , Gregory J. McHugo , and Gary R. Bond . 1998 . "Review of Integrated Mental Health and Substance Abuse Treatment for Patients with Co-Occurring Disorders.” Schizophrenia Bulletin 24 : 589 - 608 .

20. Duncan , Greg J. , Bessie Wilkerson , and Paula England . 2006 . "Cleaning up Their Act: The Effects of Marriage and Cohabitation on Illicit and Illicit Drug Use.” Demography 43 : 691 -710 .

21. Ellickson, Phyllis L. , Rebecca L. Collins, and Robert M. Bell . 1999 . “Adolescent Use of Illicit Drugs Other than Marijuana: How Important is Social Bonding and for Which Ethnic Groups?” Substance Use \& Misuse 34 : 317 - 346 .

22. Farrington , David P. , Lloyd E. Ohlin , and James Q. Wilson . 1986 . "Understanding and Controlling Crime: Toward a New Research Strategy.” Criminology 24 : 799 - 808 .

23. Ford , Jason A. 2008a . "Nonmedical Prescription Drug Use among College Students: A Comparison between Athletes and Nonathletes.” Journal of American College Health 57 : 211 219 .

24. _ 2008b . "Nonmedical Prescription Drug Use and Delinquency: An Analysis with a National Sample.” Journal of Drug Issues 38 : 493 - 516 .

25. _ . 2008c . "Social Learning Theory and Nonmedical Prescription Drug Use among Adolescents.” Sociological Spectrum 28 : 299 - 316 .

26. _ . 2009 . "Nonmedical Prescription Drug Use among Adolescents the Influence of Bonds to Family and School.” Youth \& Society 40 : 336 - 352 .

27. Ford , Jason A. and Meagan C. Arrastia . 2008 . "Pill-Poppers and Dopers: A Comparison of Non-Prescribed Prescription Drug Use and Illicit/Street Drug Use among College Students.” Addictive Behaviors 33 ( 7 ): 934 - 941.

28. Ford , Jason A. and Ryan D. Schroeder . 2009 . "Academic Strain and Nonmedical Use of Prescription Stimulants among College Students.” Deviant Behavior 30 : 26 - 53 .

29. Giordano , Peggy C. 2003 . "Relationships in Adolescence.” Annual Review of Sociology 29 : $257-281$.

30. Giordano , Peggy C. , Stephen A. Cernkovich , and Donald D. Holland . 2003 . "Changes in Friendship Relations over the Life Course: Implications for Desistance from Crime.” Criminology 41 : 293 - 327 . 
31. Giordano , Peggy C. , Stephen A. Cernkovich , and Jennifer L. Rudolph . 2002 . "Gender, Crime, and Desistance: Toward a Theory of Cognitive Transformation.” American Journal of Sociology 107 : 990 - 1064 .

32. Gottfredson, Michael and Travis Hirschi. 1987. "The Methodological Adequacy of Longitundinal Research on Crime.”Criminology 25(3):581-614.

33. Green , Carla A. and Clyde R. Pope . 1999 . "Gender, Psychosocial Factors and the Use of Medical Services: A Longitudinal Analysis.” Social Science and Medicine 48 ( 10 ): 1363 - 1372

34. Hall , Martin T. , Matthew O. Howard, and Sean Esteban McCabe . 2010 . "Prescription Drug Misuse among Antisocial Youths.” Journal of Studies on Alcohol and Drugs 71 : 917 - 924

35. Han , Beth , Joseph C. Gfroerer, James D. Colliver , and Michael A. Penne . 2009 . "Substance Use Disorder among Older Adults in the United States in 2020.” Addiction 104 : 88 96 .

36. Harrell , Zaje A. T. and Clifford L. Broman . 2009 . "Racial/Ethnic Differences in Correlates of Prescription Drug Misuse among Young Adults.” Drug and Alcohol Dependence 104 : 268 271 .

37. Hartwell , Stephanie 2003 . "Deviance over the Life Course: The Case of Homeless Substance Abusers.” Substance Use \& Misuse 38 : 475 - 502 .

38. Havens , Jennifer R. , April M. Young, and Christopher E. Havens . 2011 . "Nonmedical Prescription Drug Use in a Nationally Representative Sample of Adolescents Evidence of Greater Use among Rural Adolescents.” Archives of Pediatrics \& Adolescent Medicine 165 : 250 -255 .

39. Haynie , Dana L. , Peggy C. Giordano , Wendy D. Manning , and Monica A. Longmore . 2005 . “Adolescent Romantic Relationships and Delinquency Involvement.” Criminology 43 : $177-210$.

40. Herman-Stahl , Mindy A. , Christopher P. Krebs , Larry A. Kroutil , and David C. Heller . 2007 . "Risk and Protective Factors for Methamphetamine Use and Nonmedical Use of Prescription Stimulants among Young Adults Aged 18 to 25.” Addictive Behaviors32 : 1003 1015 .

41. Hirschi , Travis. 1969 . Causes of Delinquency . Berkeley : University of California Press .

42. Hoffmann , John P. 1995 . "The Effects of Family Structure and Family Relations on Adolescent Marijuana Use.” International Journal of the Addictions 30 : 1207 - 1241 . 
43. Hohmann , Ann A. 1989 . "Gender Bias in Psychotropic-Drug Prescribing in Primary Care.” Medical Care 27 : 478 - 490 .

44. Iguchi , Martin Y., Leonard Handelsmem , Warren K. Bickel , and Roland R. Griffiths . 1993 . "Benzodiazepine and Sedative Use/Abuse by Methadone Maintenance Clients." Drug and Alcohol Dependence 32 ( 3 ): 257 - 266.

45. Jamison , Robert N. , Stephen F. Butler , Simon H. Budman , Robert R. Edwards , and Ajay D. Wasan . 2010 . "Gender Differences in Risk Factors for Aberrant Prescription Opioid Use.” Journal of Pain $11: 312-320$.

46. Johnston, Lloyd D. , Patrick M. O'Malley and Jerald G. Bachman . 2005 . "Monitoring the Future National Survey Results on Drug Use, 1975-2004. Volume II: College Students and Adults Ages 19-45” in NIH publication No. 05-5728 . Bethesda , MD : National Institute on Drug Abuse, U.S. Dept. of Health and Human Services, National Institutes of Health .

47. Kelly Judith P ., Suzanne F. Cook, David W. Kaufman, Theresa Anderson, Lynn Rosenberg, and Allen A. Mitchell . 2008 . "Prevalence and Characteristics of Opioid Use in the U.S. Adult Population.” Pain 138 ( 3 ): 507 - 513 .

48. Kreider, Rose M. 2010 . "Increase in Opposite-Sex Cohabiting Couples from 2009 to 2010 in the Annual Social and Economic Supplement (ASEC) to the Current Population Survey (CPS).” Washington, DC: U.S. Census Bureau, Housing and Household Economic Statistics Division. Retrieved on January 20, 2013 (http://www.census.gov/hhes/families/files/Inc-Oppsex-2009-to-2010.pdf)

49. Krohn , Marvin D. , Alan J. Lizotte , and Cynthia M. Perez . 1997 . "The Interrelationship between Substance Use and Precocious Transitions to Adult Statuses." Journal of Health and Social Behavior $38: 87-103$.

50. Laub , John H. and Robert J. Sampson . 2003 . Shared Beginnings, Divergent Lives: Delinquent Boys to Age 70 . Cambridge, MA : Harvard University Press .

51. Laub , John H. , Daniel S. Nagin , and Robert J. Sampson . 1998 . "Trajectories of Change in Criminal Offending: Good Marriages and the Desistance Process.” American Sociological Review $63: 225-238$.

52. Lui , Xiaoru and Howard B. Kaplan . 2001 . "Role Strain and Illicit Drug Use: The Moderating Influence of Commitment to Conventional Values.” Journal of Drug Issues 31 : 833 -856 .

53. Maume , Michael O. , Graham C. Ousey , and Kevin Beaver . 2005 . "Cutting the Grass: A Reexamination of the Link between Marital Attachment, Delinquent Peers and Desistance from Marijuana Use.” Journal of Quantitative Criminology 21 : 27 - 53 . 
54. McCabe , Sean Esteban and Christian J. Teter . 2007 . "Drug Use Related Problems among Nonmedical Users of Prescription Stimulants: A Web-Based Survey of College Students from a Midwestern University.” Drug and Alcohol Dependence 91 : 69 - 76.

55. McCabe, Sean Esteban , Christian J. Teter , and Carol J. Boyd . 2006 . "Medical Use, Illicit Use, and Diversion of Abusable Prescription Drugs.” Journal of American College Health 54 : $269-278$.

56. McCauley, Jenna L. , Amanda B. Amstadter, Carla K. Danielson, Kenneth J. Ruggiero, Dean G. Kilpatrick, and Heidi S. Resnick. 2009. "Mental Health and Rape History in Relation to Nonmedical Use of Prescription Drugs in a National Sample of Women.” Addictive Behaviors 34:641-648.

57. Messner, Michael A. 1992 . Power at Play: Sports and the Problem of Masculinity . Boston : Beacon Press .

58. Noone, Jack H. and Christine Stephens . 2008 . "Men, Masculine Identities, and Health Care Utilisation.” Sociology of Health and Illness 30 ( 5 ): 711 - 725 .

59. Osborn , S. G. and D. West . 1979 . "Marriage and Delinquency: A Postscript.” British Journal of Criminology $18: 254-256$.

60. Paulozzi , L. J. and Y. L. Xi . 2008 . "Recent Changes in Drug Poisoning Mortality in the United States by Urban-Rural Status and by Drug Type.” Pharmacoepidemiology and Drug Safety 17 : $997-1005$.

61. Peralta , Robert L. and Jennifer L. Steele . 2010 . "Nonmedical Prescription Drug Use among U.S. College Students at a Midwest University: A Partial Test of Social Learning Theory." Substance Use \& Misuse 45 : 865 - 887.

62. SAMHSA . 2003 . "Misuse of Prescription Drugs.” Substance Abuse and Mental Health Services Administration, Rockville, MD: Office of Applied Studies.

63. — . 2010 . "Results from the 2010 National Survey on Drug Use and Health: National Findings.” Office of Applied Studies, Washington, DC. Retrieved on August 16, 2011 (http://www.samhsa.gov/data/NSDUH/2k10NSDUH/2k10Results.htm)

64. Sampson , Robert J. and John H. Laub . 1990 . "Crime and Deviance over the Life Course The Salience of Adult Social Bonds.” American Sociological Review 55 : 609 - 627 .

65. Sampson , Robert J. and John H. Laub . 1993 . Crime in the Making: Pathways and Turning Points through Life . Cambridge , MA : Harvard University Press . 
66. Sampson, Robert J. , John H. Laub , and Christopher Wimer . 2006 . "Does Marriage Reduce Crime? A Counterfactual Approach to within-Individual Causal Dffects.” Criminology 44 : 465 - 508 .

67. Seaman , Christen N. and Keith Zullig . 2011 . "Nonmedical Prescription Drug Use among College Students and Athletic Involvement.” Research Quarterly for Exercise and Sport 82 : A82 - A83 .

68. Seydlitz, Ruth and Pamela Jenkins . 1998 . "The Influence of Families, Friends, Schools, and Community on Delinquent Behavior.” Pp. 53 - 97 in Delinquent Violent Youth: Theory and Interventions, edited by T. P. Gullotta , G. R. Adams, and R. Montemayor . Thousand Oaks , CA : Sage .

69. Schroeder , Ryan D. and Jason A. Ford . 2012 . "Prescription Drug Misuse: A Test of Three Competing Criminology Theories.”Journal of Drug Issues 42 : $4-27$.

70. Shover, Neal. 1996 . Great Pretenders: Pursuits and Careers of Persistent Thieves . Boulder , CO : Westview Press .

71. Simoni-Wastila, Linda. 1998 . “Gender and Psychotropic Drug Use.” Medical Care 36 : 88 -94 .

72. Simoni-Wastila , Linda, Grant Ritter , and Gail Strickler . 2004 . "Gender and Other Factors Associated with the Nonmedical Use of Abusable Prescription Drugs.” Substance Use \& Misuse $39: 1-23$.

73. Smock , Pamela J. 2000 . "Cohabitation in the United States: An Appraisal of Research Themes, Findings and Implications.”Annual Review of Sociology $26: 1-20$.

74. Sokol-Katz , Jan , Roger Dunham, and Rick Zimmerman . 1997 . "Family Structure versus Parental Attachment in Controlling Adolescent Deviant Behavior: A Social Control Model.” Adolescence 32 : 199 - 215 .

75. Thompson , Melissa and Milena Petrovic . 2009 . "Gendered Transitions within-Person Changes in Employment, Family, and Illicit Drug Use.” Journal of Research in Crime and Delinquency $46: 377-408$.

76. UNODC . 2011 . The Non-Medical Use of Prescription Drugs. United Nations Office on Drugs and Crime, Vienna.

77. Wallace , Jr. John M. 1998 . "Explaining Race Differences in Adolescent and Young Adult Drug Use: The Role of Racialized Social Systems.” Drugs and Society 41 : 21 - 36 .

78. Warr , Mark. 1993 . “Age, Peers, and Delinquency.” Criminology 31 : 17 - 40 . 
79. — 2002 . Companions in Crime: The Social Aspects of Criminal Conduct . New York : Cambridge University Press .

80. West, Candace and Don H. Zimmerman . 1987 . Gender and Society 1 ( 2 ): 125 - 151 .

81. West , Donald J. 1982 . Delinquency: Its Roots, Careers, and Prospects . London : Heinemann .

82. Wiatrowski , Michael D. , David B. Griswold, and Mary K. Roberts . 1981 . "Social Control Theory and Delinquency.” American Sociological Review 46 : 525 - 541 .

83. Yamaguchi , Kazuo and Denise B. Kandel . 1985 . "On the Resolution of Role Incompatibility: A Life Event History Analysis of Family Roles and Marijuana Use.” American Journal of Sociology 90 : $1284-1325$. 